\title{
The World's Oldest Bridges - Mycenaean Bridges
}

\author{
Karas Slawomir ${ }^{1, *}$, Nien-Tsu Tuan ${ }^{2}$ \\ ${ }^{1}$ Road and Bridge Department, Lublin University of Technology \\ ${ }^{2}$ University of Cape Town, South Africa \\ *Corresponding author: s.karas@pollub.pl
}

\begin{abstract}
The ancient bridges and their remnants located in the vicinity of Mycenae and Arkadico villages are considered to be the world's oldest bridges. The bridges were built with massive irregular limestone blocks, called Cyclopean boulders, in the Bronze Age. Two of the four objects discussed here are still in operation, occasionally used for the needs of local agriculture. The bridges are classified as clapper schemes, but a lot points to the parallel use of the arch bridge technology. The remnants of the bridge in the vicinity of the modern village of Mycenae, due to the significant width of the riverbed, suggest that it might have been the longest among Mycenaean bridges. Probably, it was a multi-span bridge. The structures of the discussed bridges have flat bottom platforms that stabilize the walls of the bridge openings and protect them against washing out. The technological problem of the bridge keystone installation was investigated in the cases of corbel and arch systems.
\end{abstract}

Keywords: Mycenaean bridges, corbel structures, human heritage

Cite This Article: Karas Slawomir, and Nien-Tsu Tuan, "The World's Oldest Bridges - Mycenaean Bridges." American Journal of Civil Engineering and Architecture, vol. 5, no. 6 (2017): 237-244. doi: 10.12691/ajcea-5-6-3.

\section{Introduction}

Undoubtedly, the oldest bridges are those created by tectonic activity, the fluvial and/or aeolian erosion processes. However, such bridges i.e. natural bridges are not the focus of this paper. Here, only man made bridges and their remains are considered.

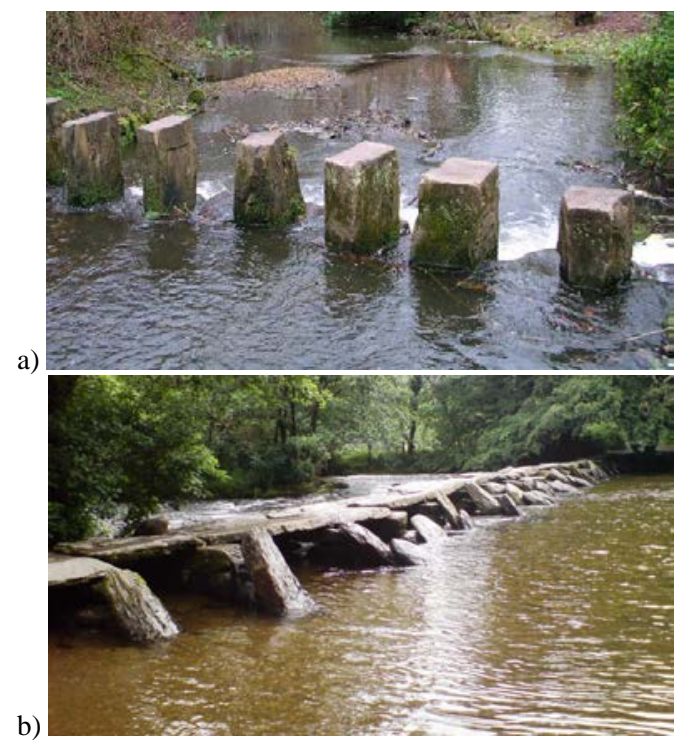

Figure 1. Simple stone footbridge a) stepping stones ${ }^{1}$ b) Tarr Steps ${ }^{2}$ footbridge

\footnotetext{
${ }^{1}$ Sourced from https://endellionbarge.files.wordpress.com/2014/05/tarrsteps-clapper-bridge.jpg; photo by Charlesdrakew

${ }^{2}$ Sourced from http://www.bristol.ac.uk/civilengineering/bridges/Pages/ NotableBridges/TarrSteps.html; photo by David Blockley.
}

Whenever a discussion on the oldest bridges starts, clapper bridges are usually recalled and, as an example, the spectacular Tarr Steps ${ }^{3}$ in England, Figure 1.b.

In Figure 1.a, the stepping stones illustrate the development to a more advanced clapper bridge. Although the exact age of Tarr Steps is unknown, it is estimated they were constructed in the period between 3,000 B.C. and medieval times.

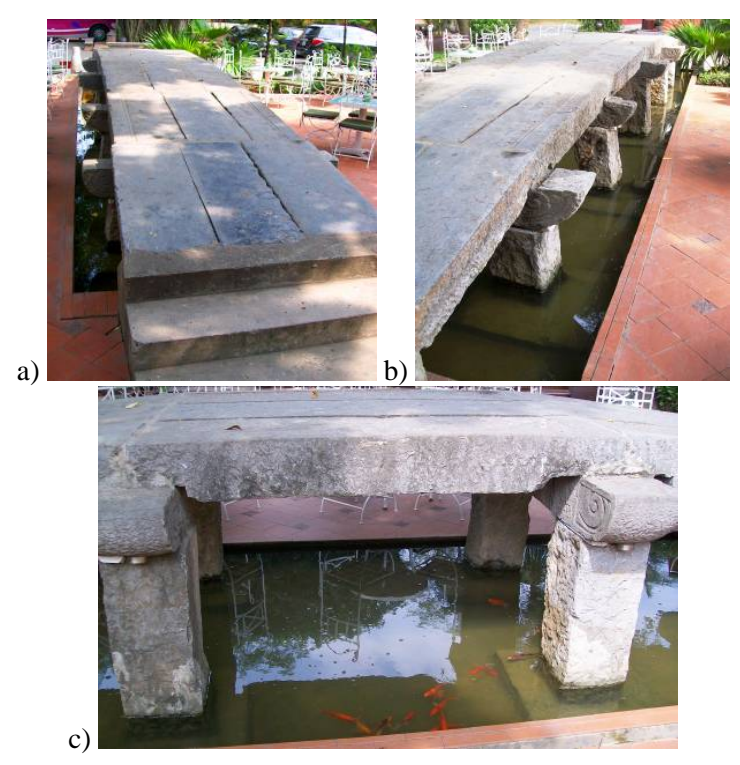

Figure 2. Clapper bridge, Hanoi, a-b) views c) the span

The lower time limit probably results from the fact that it is a very simple structure. Figure 2 shows a very elegant, $18^{\text {th }}$ century clapper bridge, exhibited in the Hanoi National Museum of Vietnamese History. Even if its

\footnotetext{
${ }^{3}$ Scheduled Monument 1021325: Tarr Steps
} 
structural elements were worked to the master level, it is still the same simple structure as the Tarr Steps.

The ancient bridges similar to the Mycenaean bridges built in other continents in the centuries BC are scant. For example, the documented history reveals that the bridges built in China around 1200 BC, such as the floating bridges, are mostly made of wood [1]. The unearthed archaeological evidences reveals that the bridges built in $\mathrm{Xi}$ 'an, the capital of Shaanxi province, dating back to 200 BC approximately, were built with wood as well, Figure 3 [2].

Leaving aside the priority of the clapper bridge, two bridges in the vicinity of Arkadico, Peloponnese, Greece, can be deemed the oldest existing bridges. They have not been precisely dated. The most often quoted period is the Bronze Age, i.e. 1,300 - 1,190 B.C. Both bridges are accessible to tourists and occasionally used in local agricultural transport. Apart from the aforementioned bridges in the Mycenae area, there are also remains of two other bridges to be found. Hence, four structures discussed in the paper.

The technical subject literature here is poor. There are two archeological papers on bridges and other engineering structures. Chapter 7 of A. Jansen's book [3] contains a map of the roads around Mycenae and some mentions of the bridges, although without giving their location or description. A similar archeological approach can be found in Simpson and Hagel's monograph [4]. A more extensive overview and discussion of bridges in antiquity appears in B. Bougia's doctoral thesis [5], while J. Briegleb's [6] and A. Nakassis's [7] works offer a more synthetic account of the question of stone bridges, where the latter concerns the bridge located in Eleutherna, on Crete. This bridge is not included in the paper as it is not a Mycenaean bridge, however, its structure does draw on the Mycenaean corbel bridges. It is dated to the Hellenistic period.

This paper develops themes from Karaś's and Kowal's work [8] which contains a static analysis of both existing Mycenaean bridges, conducted on the basis of an inventory of the sizes of Cyclopean boulders. The most stressed areas were indicated and a comparison of the structures of the bridges with similar elements of the fortress of Tiryns and Mycenaean tombs was conducted.

\section{Location of the Objects In Question}

Figure 4 is a contemporary Google map showing Mycenaean settlement sites, two functioning bridges, and two Mycenaean bridge remains.

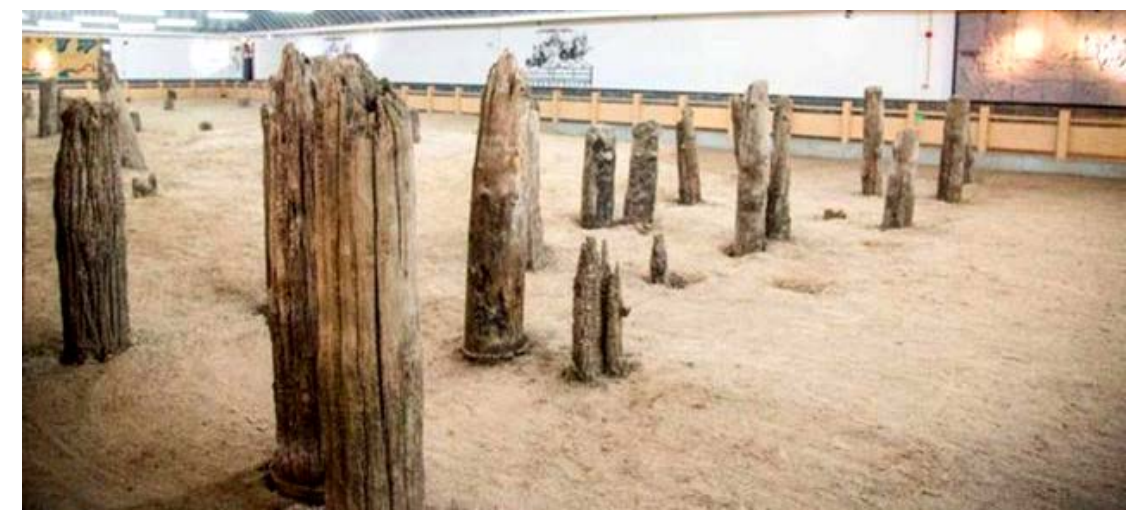

Figure 3. The bridges built in Xi'an (Sourced from https://kknews.cc/travel/oo8bjpm.html)

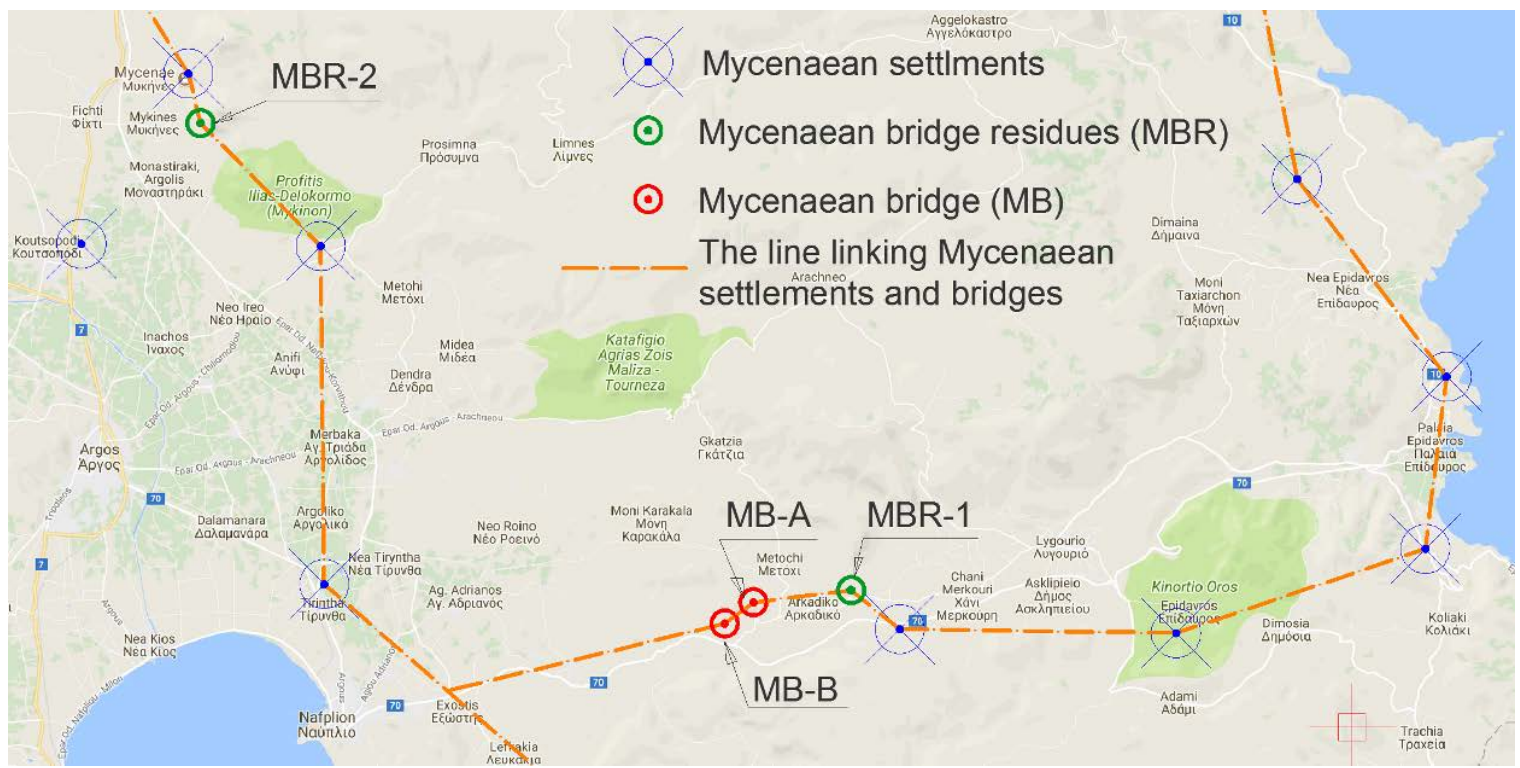

Figure 4. Locations of Mycenaean bridges, Mycenaean bridge remains and Mycenaean settlement as well as a simplified sketch of their mutual connections (Sourced from https://upload.wikimedia.org/wikipedia/commons/0/0b/Path3959-83.png; titled: Map of Mycenaean Greece 1400-1200 BC: Palaces, main cities and other settlements) 
The functioning bridges have touristic names. They are called as follows, respectively:

- Kazarma Bridge - Mycenaean bridge A (MB-A), Figure 5.a,

- Petrogephyri Bridge - Mycenaean bridge B (MB-B), Figure 5.c.

The bridges are situated along a Mycenaean road which links Mycenae, Tiryns, Tolo and Epidaurus - have linked before and links today, too. Today, the road is called

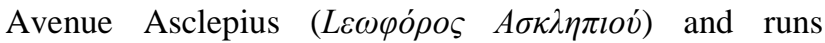
together with the new road number 70, see Figure 4.

In the village of Arkadico there is also a remnant of another Mycenaean bridge. In Figure 4, it is marked as MBR-1, after its full name, Mycenaean Bridge Residuum 1. In this case, only the structure of cyclopean boulders reminds of the ancient bridge of earlier times, Figure 6.a. Right next to the water inflow side of the bridge, an agricultural road runs to the neighbouring olive groves, Figure 6.b.

a)

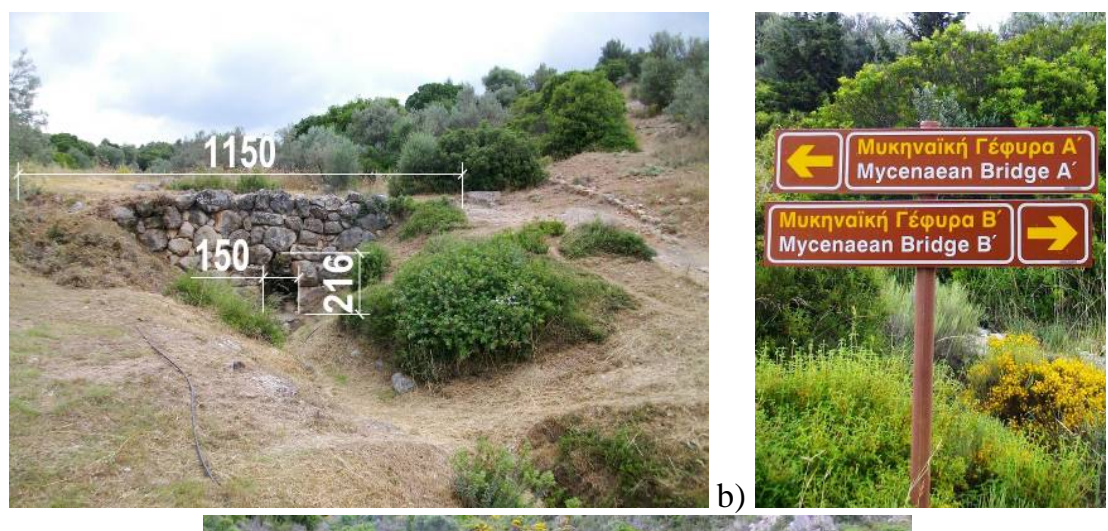

c)

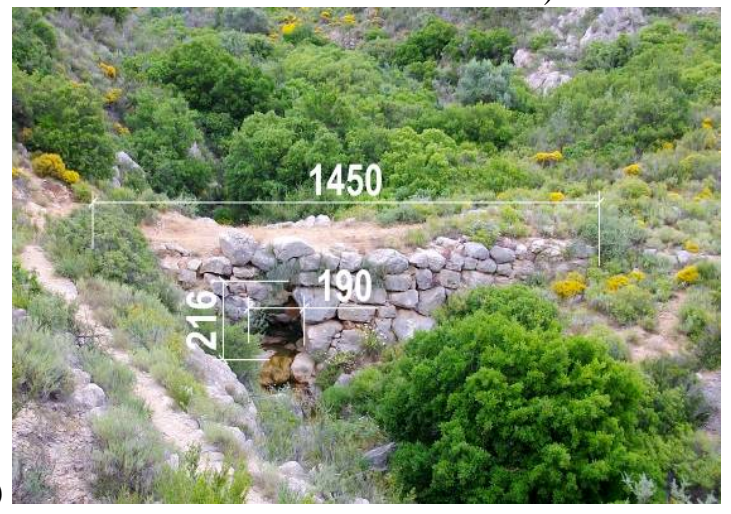

Figure 5. Mycenaean bridges near the village of Arkadico a) MB-A b) guide post c) MB-B

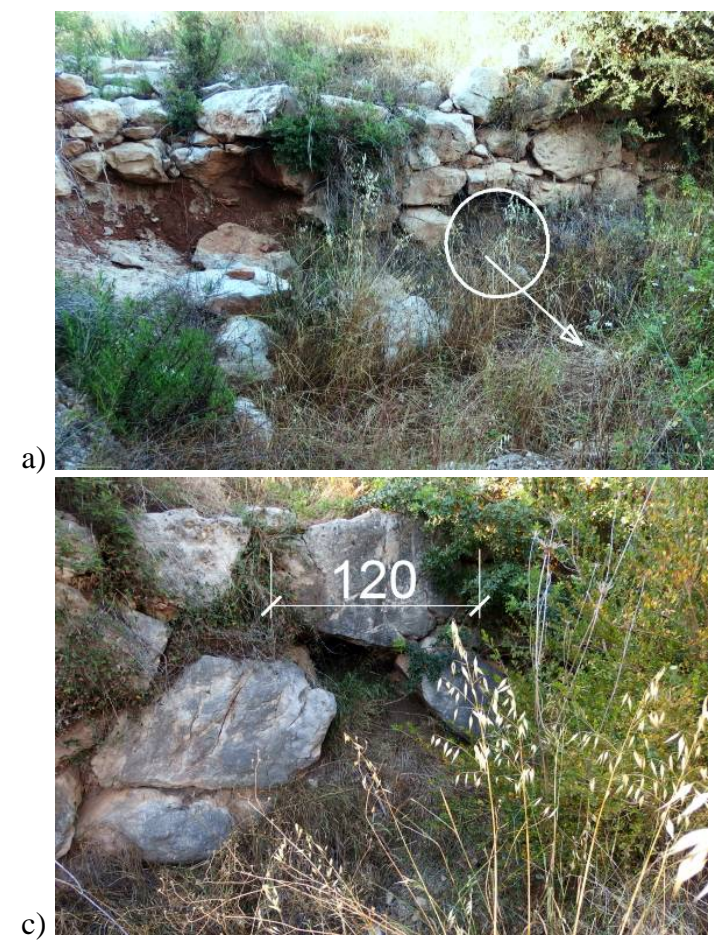

d)

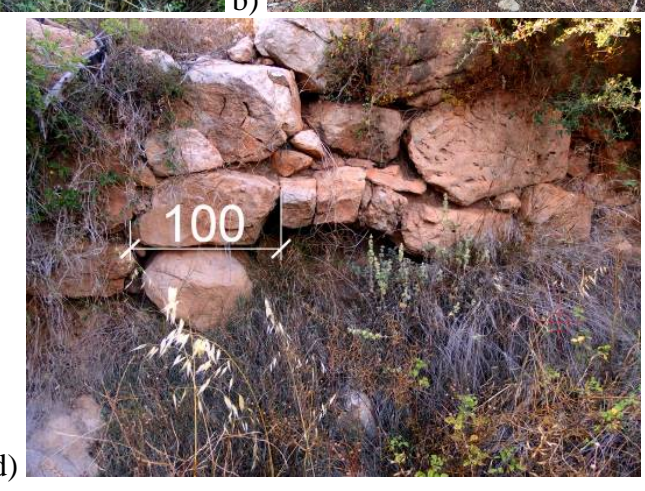

Figure 6. The remnants of the Mycenaean bridge in the village of Akadico a) overall view from the outlet perspective b) the rural road running along the bridge c-d) outlets; dimensions in [cm] 
In the technical sense, the bridge does not work at all. It is rather an unprotected archaeological site. There is no clear watercourse, although the ground is naturally moist. That proves the unchangeability of waterways since the Mycenaean times.

Nevertheless, two narrow openings - spans are easily noticeable. Currently, they do not function at all. Only the boulder system of the vaulting arch allows the presumption of their previous bridge function, Figure 6.c-d. The two dimensions of cyclopean boulders give a metric reference to the dimensions of the whole structure.

In Figure 7, another remnant of a Mycenaean bridge is shown. In Figure 4, the place is marked as MBR-2. Visible fragments are situated in the mountain valley of a dry riverbed at the end of the contemporary Mycenae village. From the characteristic, small church of Agios Ioannis to the ancient Mycenae fortress runs a road about $1 \mathrm{~km}$ long, parallel to the valley.

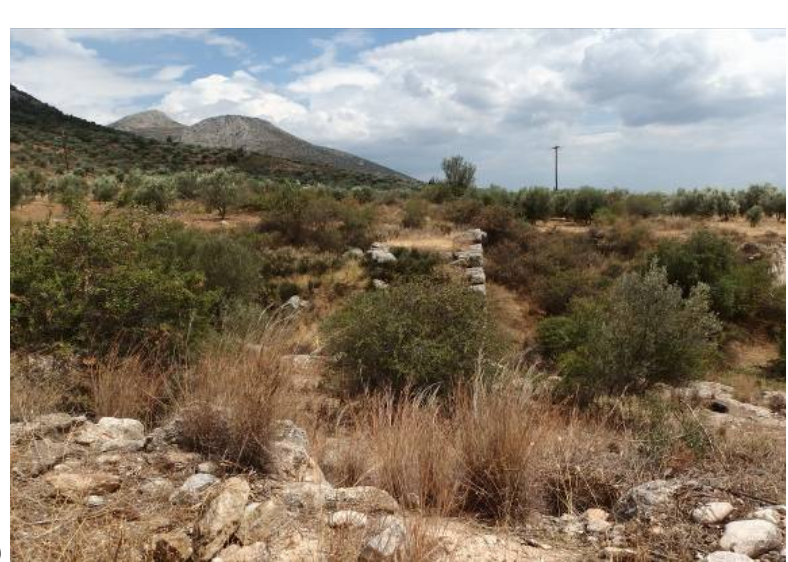

Figure 7. Abutment remains of a Mycenaean bridge a) side view b) "cross-section"
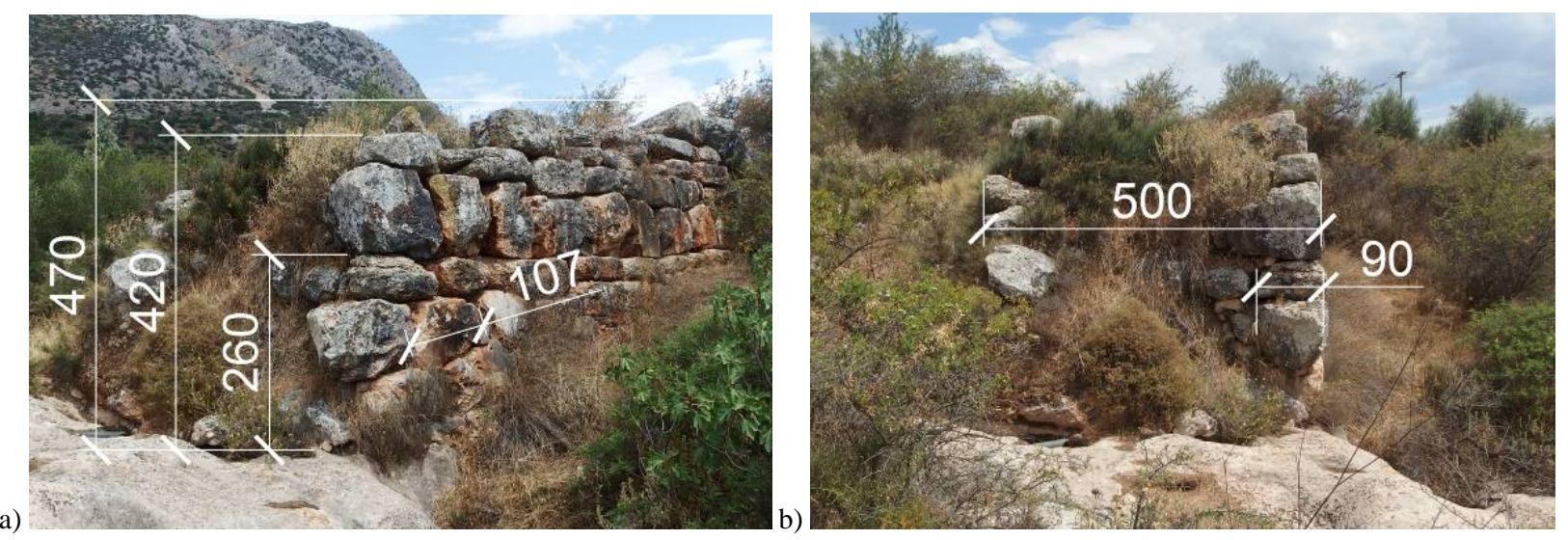

Figure 8. The remains of the Mycenaean bridge abutment near the village of Mycenae, dimensions of the structural elements a) side view b) width; [cm]

This monument has not been thoroughly described, therefore, the following photographs contain its basic dimensions, Figure 8. The width of the dry riverbed in the widest point amounts to approx. $40 \mathrm{~m}$, which means that the width of the bridge was similar. Hence, it might be the longest Mycenaean bridge. Consequently, one can assume that it was a multi-span bridge. The abutment is situated on the left river bank, perpendicularly to the axis of the periodic watercourse. The bottom of the watercourse is smooth, solid rock of a levelled elongated slope dominating at the bridge width $\mathrm{i}=0.1$. Right behind the bridge the slope is much steeper and equals $\mathrm{i}=0.4$.

Unfortunately, it is difficult to guess the dimensions of the span light, even roughly. The measurements were taken by means of a tape and are given in [cm].

The determined maximum width of the abutment is $\mathrm{B}=5 \mathrm{~m}$. Taking into consideration the possibility of the existence of bilateral stone balustrades of the width of $2 \mathrm{x}$ $0.6 \mathrm{~m}=1.2 \mathrm{~m}$, a utility width of the bridge $\mathrm{B}_{0}=3.8 \mathrm{~m}$ is obtained which corresponds to the width required for a two horse chariots to pass, e.g. Egyptian chariots of
Tutankhamun's times of the width of $1.03 \mathrm{~m}$ [9]. The width of the side Cyclopean boulder walls amounts approx. to $1 \mathrm{~m}$. The maximum height, measured from the bottom of the dry watercourse, amounts up to $4.7 \mathrm{~m}$.

\section{Technology of Mycenaean bridges}

A thorough examination of the structure of the bridges is not possible due to the fact that they are monuments under strict protection. Hence, the discussion here will be based only on their images and external dimensions.

The present image of the bridges is far removed from the original one, nevertheless, the current arrangement of Cyclopean boulders is the only attainable reference. The following concepts may be therefore equally right or wrong. In the bridge construction unwrought sizeable stones called Cyclopean boulders were used - a common building material in Peloponnese. They were marble - metamorphic rock resulting from the limestone metamorphosis. 
In such circumstances, the basic construction issue was the boulder selection and transport over short distances, approx. $100 \mathrm{~m}$.

When comparing the images in Figure 9 - Figure 10, at least three construction methods can be distinguished.

In the construction of the bridges in Figure $9 \mathrm{a}-\mathrm{b}$, Cyclopean boulders of similar size were used, see [8]. A fragment of the abutment, Figure 9.a, is a complex structure. In the bottom part sizeable boulders were used, laid on a natural rocky ground. Above, a horizontal plate platform, providing stability for the bottom boulders and, at the same time, a basis for another layer of

a)

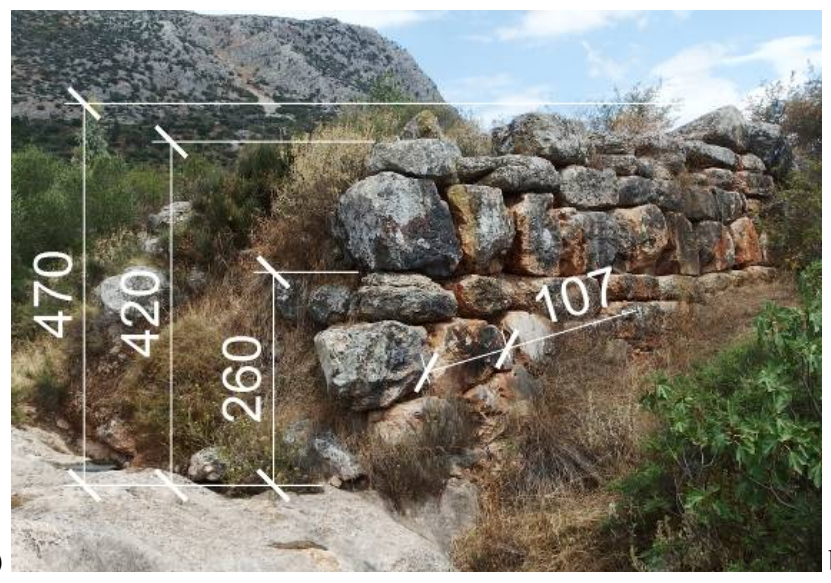

upper boulders, was noticeably put. The shapes of the outlines of the external surfaces resemble squares or vertical rectangles. Further above, there is another platform where, probably, stones constituting the road were placed. In modern terms, one can speak of mechanically stabilized rocks. It was not entirely possible to examine the scope of platforms, however, a lot points to the fact that the platforms formed surfaces on the whole horizontal cross-section of the abutment structure. If that were the case, the structure in question would be technically more advanced than bridges MB-A and MB-B.

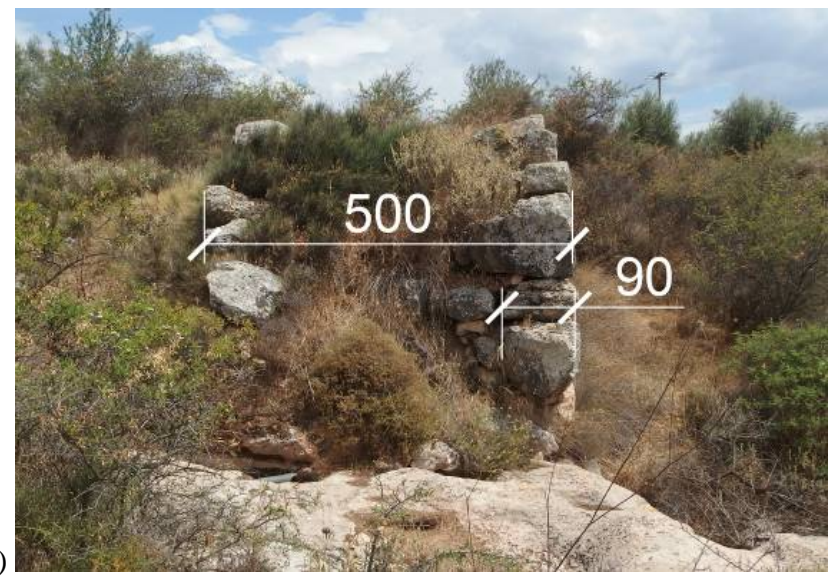

Figure 9. Cyclopean boulder system visible from the bridge outlets a) MBR-2 b) MB-A

Bridge MB-A, Figure 9.b., is classified as a corbel bridge, despite the fact that its present condition corresponds to an arch bridge of a clumsy arch vault. Leaning towards the concept of corbel bridge, one can distinguish, with a high degree of arbitrariness, support plates through conjoining neighbouring boulders, see Figure 2.a in [10]. The bridge spandrels were made of chosen boulders, whereas their arrangement is chaotic, the bottom of the walls of the side abutments resembles the shape of the river bed. The riverbed is an artificial structure constituting a bottom slab, which in Fig. 9.b is marked symbolically with a cyan outline. The use of a bottom slab which at the outlet forms a distinct, quite high threshold testifies to an extensive hydraulic experience of the constructor.

The bottom slab stabilised the walls of the bridge opening, reduced their washing out and, as a result, their horizontal

a)

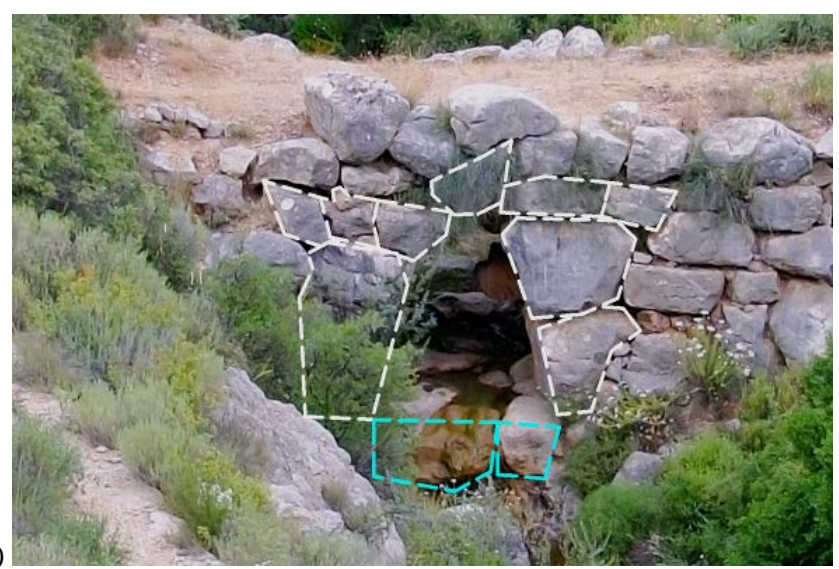

movement. The structure of the bottom slab with a few characteristic element sizes is shown in Figure 10.

a)

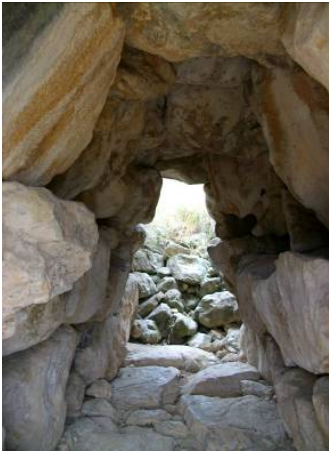

Figure 10. MB-A a) the bridge light b) bottom slab

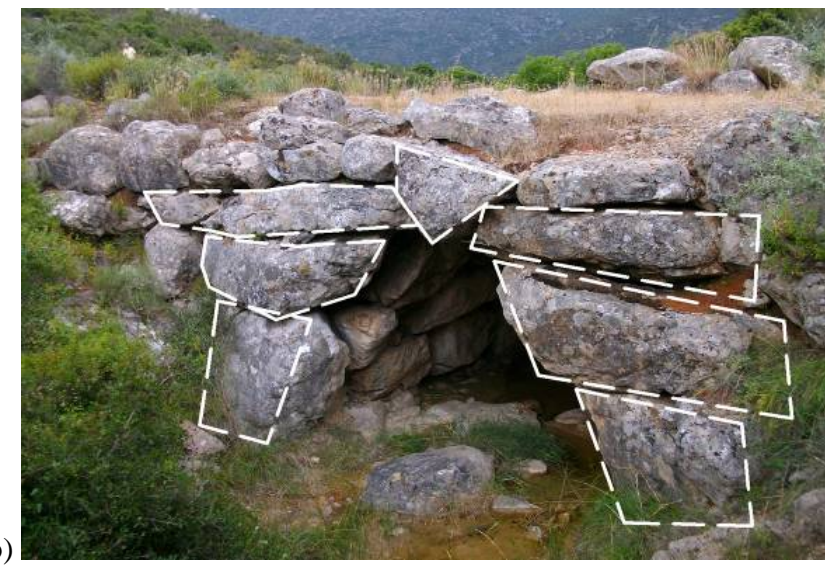

Figure 11. MB-B a) view from the outlet b) view from the inflow 
The MB-A bridge, as god Janus, has two faces, Figure 11. Here, the following problem can be discussed: whether it is a corbel bridge or an arch bridge. In the case of Figure 11.a one is almost forced to classify the bridge as an arch one, although some virtual fusion of "matching" neighbouring boulders is possible. Figure 11.b shows a corbel bridge, without question. It can be concluded, therefore, that aiming at a support construction, the builders skilfully used accessible materials, arranging them to resemble primitive arch bridges. If that were the case, one can speak about a mixed technology - a corbel bridge and an arch bridge.

A prerequisite for the application of the support scheme is a relative ease of drawing marble plates, even more so with regard to the fact that a perfect marble lubricant was available, i.e. water. With high probability approaching certainty, it can be assumed that in the support system it was not necessary to use scaffolding. Only fixing a boulder in the key required some rolling or a turn at the moment of placing it in its final position.

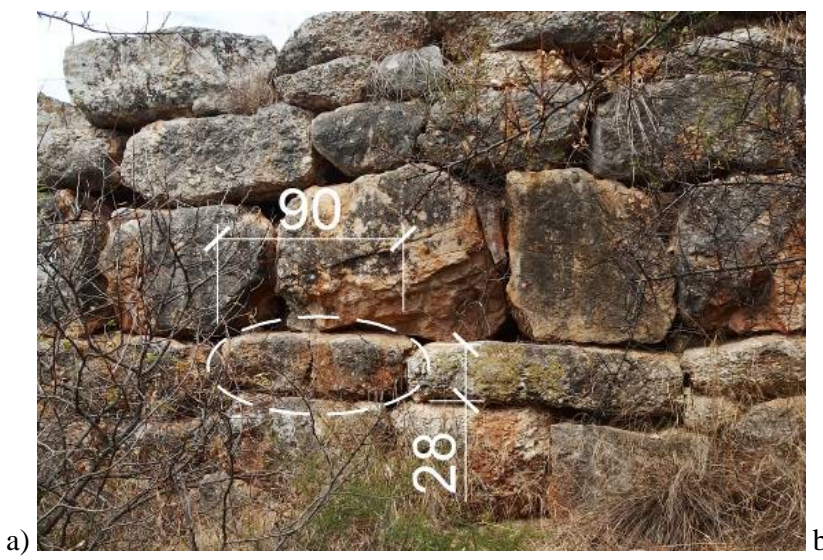

The technology of the Cyclopean boulder arch bridge was much more demanding. Rolling subsequent boulders and putting them in position required temporary supports. Even if shores had been primitive and easy to arrange, the process required a good sense of the mass of elements and their weight. Nowadays, it is known as structural mechanics.

Figure 11 a shows again a bottom slab outlined with a cyan dash line.

Applying the method of the mental joining of neighbouring boulders is justified, even at the high risk of error. Cracking of boulders resulting in a new arrangement of a "momentary" balance stems from seismic activity in Peloponnese and Greece as such. Slight tremors occur several times a day. Large scale earthquakes happen rarely, however, not more seldom than once a century. In the case of Mycenaean bridges, seismic influences combined with significant weights of Cyclopean boulders and a material which is not particularly resistant to shearing and bending, i.e. marble, result in systematic increase in boulder cracking and moving, Figure 12 - Figure 13.

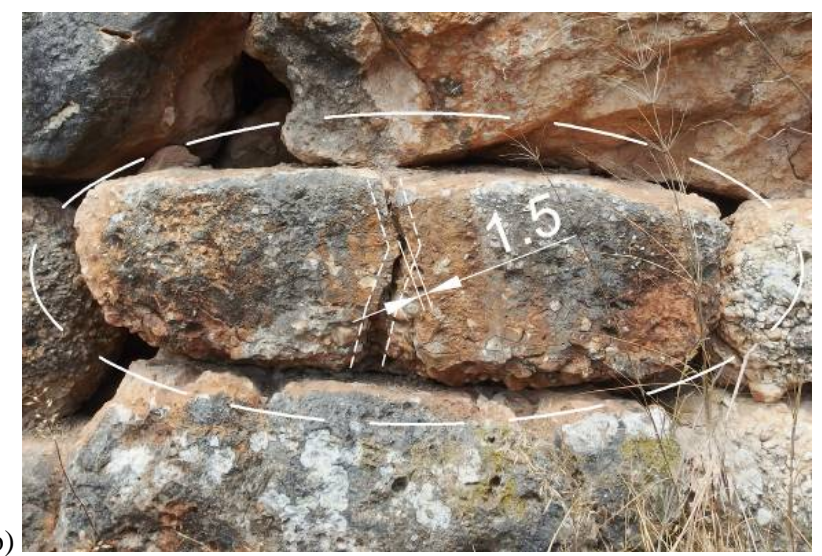

Figure 12. MBR-2 a) a new vertical crack in the platform slab b) magnification; [cm]

Seismic activity threatens the existence of MB-B. In Figure 12, the areas of the greatest material stress, determined in the static analysis, are outlined in red [8].

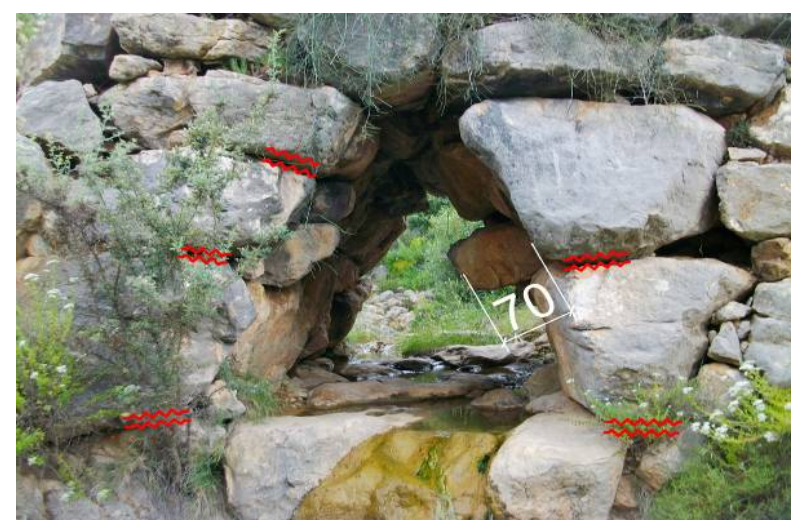

Figure 13. Protrusion of a structural boulder, technically very risky

As a result of achieving the limit state of balance, one of the boulders was pushed inside the bridge opening by approx. $70 \mathrm{~cm}$. If the protrusion proceeds, sequential destruction of the whole internal wall will take place. Bearing in mind the procedure in the case of a unique monument, its structure should be secured by an efficient and archeologically acceptable method.

\section{Use of Temporary Scaffolding}

The closing of an arc or corbel structure by putting a keystone is always a critical moment. A key changes an erected wall structure into a vault by inducing a thrust in the headboard/base. As the forces in the vault are transmitted to the foundation, the arch will push outward at the base and the force is called thrust. Vault structures are very stiff and durable, see Figure 14.a-b.

In Figure 14.a, underneath the flat arch, a horizontal bar carries only its dead weight. It was a typical solution during the Roman period.

In Figure 14.b, the red line marks the curve of normal compression.

At this point two terms can be distinguished. The arch stands for an architectural element and the arc means an analytical curve around which compressed stone material is arranged.

The mathematical solution for the catenary curve is a hyperbolic cosine function. However, when one expands the function in the Maclaurin series, its approximation is a parabolic function

$$
\operatorname{Cosh}(x)=\sum_{n=0,1,2,3, \ldots} \frac{x^{2 n}}{(2 n) !} \approx 1+\frac{x^{2}}{2}
$$


which in engineering arrives at

$$
y=h\left(\frac{2}{L}\right)^{2} x(L-x),
$$

where $h$ stands for an arch elevation and $L$ is an arch span.

This is the reason for the parabolic arc drawn in Figure 14.b.

As it is shown in Figure 14.c, the forces supporting the unclosed arch are not significant. The used slender steel rods have kept the structure in a proper position for more than 40 years.
Conjecturing whether scaffolding was used for placing the keystone of Mycenaean bridges implies Peircean abduction in 'explanation mode'. It is a type of inference dealing with a possible formal rule through reasoning to explain observed phenomena [11]. The logic of reasoning, according to Peirce, is an argument from rule, result to case [12]. The deductive development of hypotheses through 'if .. then' statements can be used to mirror Peircean abduction logic [13]. The sessions below apply the rule, result, and case reasoning to abduct whether scaffolding was used when placing the keystone for Mycenaean bridges.

a)
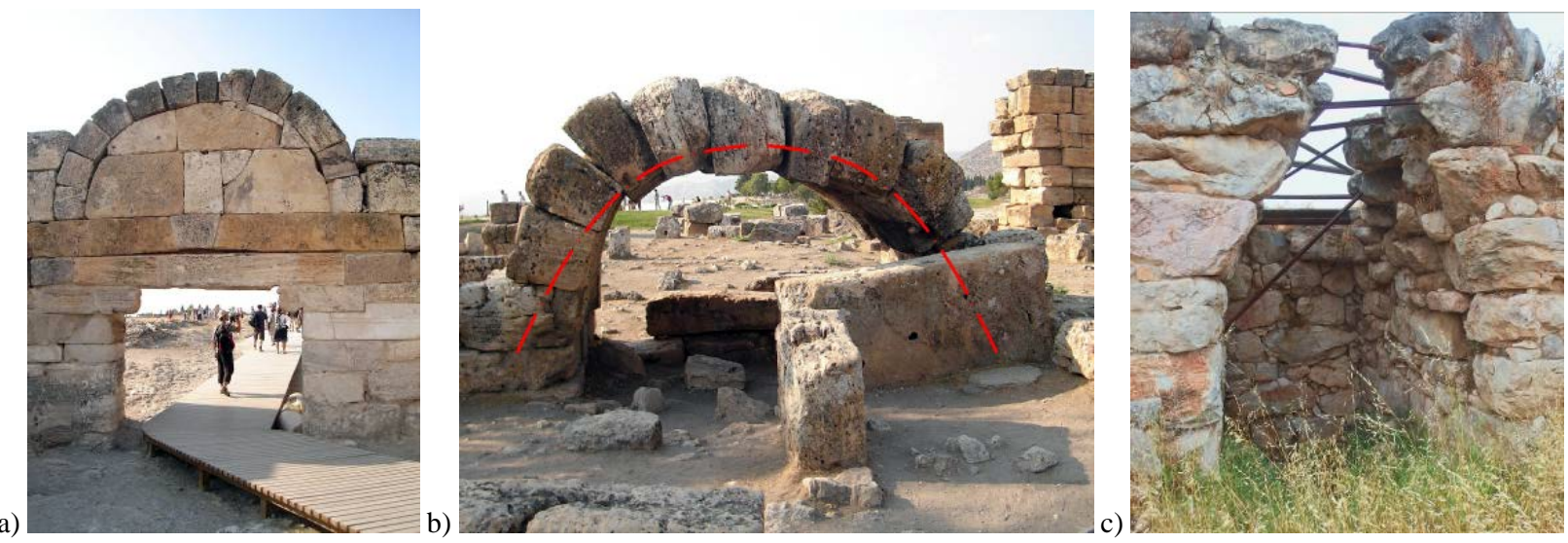

Figure 14. Vaults a) keystone causing the thrust in a flat arch b) example of the arch durability (Photos 14.a-b were taken in Hierapolis ( $I \varepsilon \rho \alpha \dot{\pi}$ ) $\lambda \iota \varsigma$ ), Phrygia, Turkey) c) scaffold supporting an unfinished roof in the Tiryns fortress

a)
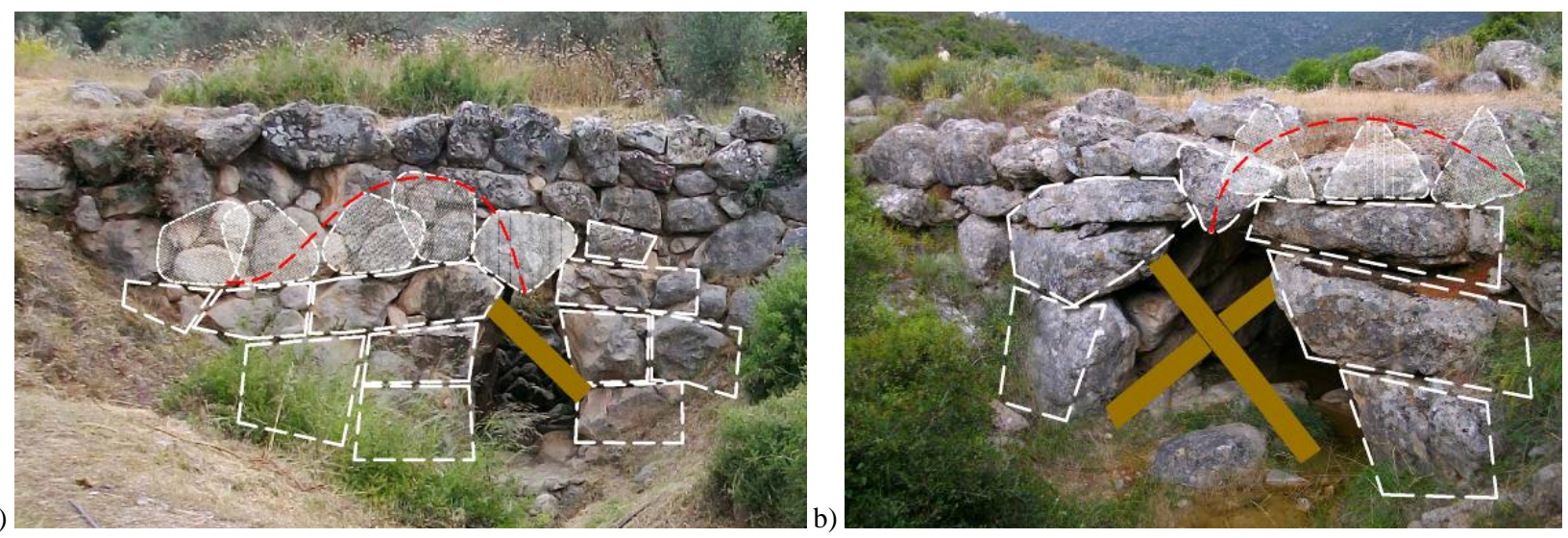

Figure 15. The keystone rolling to its final position a) the outlet wall of MB-A b) the inlet wall of MB-B

In Figure 15, an assumption of a possible boulder arrangement during the bridge construction was made. Intuitively, some of the neighbouring boulders were merged.

Under such an assumption, rolling the keystone does not require the use of scaffolding, however, in practice, a constructor usually acts conservatively and tries to secure the structure and themselves against a construction disaster. For this reason, structures stabilizing wooden beams were symbolically marked in the photographs. Used braces were certainly very helpful at the final turn of the keystone to its final position.

Furthermore, the keystone was rolled into position, due to the uneven surface, the movement of keystones could cause the merged boulders to shift, even though the sand/gravel pillows were used. Another scenario is that the keystone was pushed into the position. Under this circumstance, the merged boulder is even at a higher risk of being detached from another due to the impact caused by the push. Furthermore, the weight of the biggest keystone, determined on the basis of its dimensions, is approx. $16.5 \mathrm{kN}$. The final step might have had a dynamic impact causing the imbalance of walls and the extrusion of boulders. Therefore the assumed rule is that if the boulders of the ancient corbel-arch bridges are properly secured, the movement of the keystone is unlikely to cause the boulders extruded towards the wall. The observed result is that the boulders of Mycenaean bridges are not massively extruded towards the wall. Therefore a case (hypothesis) can be established that certain measures were likely employed to secure the boulders when placing the keystones.

The above considerations are conducted from the point of view of a contemporary construction engineer.

In both illustrations, Figure 15.a-b, the curve, geometrically analogic to a cycloid was marked with a red 
colour. The area under the curve can be seen as a measure of work necessary for the keystone course.

\section{Conclusions}

Mycenaean bridges are complex Cyclopean structures. Provided that the clapper bridge near Exmoor, which remains in operation, one should emphasise its simple structure. In this context, Mycenaean bridges are chronologically the oldest bridges in the world. Additionally, the bridge in Exmoor has been destroyed by floods and repaired many times.

Two among four Mycenaean bridges discussed in the paper have been in constant operation for at least 3,000 years. This fact puts them at the forefront of the most durable bridges in the world.

The bridges were constructed with Cyclopean boulders. Their weight varies, although the heaviest ones weigh from 10 to $20 \mathrm{kN}$.

The corbel bridge is assumed as the structural scheme, however, the conclusions indicate a mixed scheme. At certain points Cyclopean boulders were arranged according to the arch bridge scheme. Nevertheless, this conclusion can be undermined by the fact that the analyses concerned the present boulder configuration which may be a result of seismic activity.

Similarly, the use of temporary scaffolding during the construction process can be presumed. In the case of the corbel bridge scheme, scaffolding might have been redundant until the moment of fixing the keystone. If the arch bridge technology had been used, there would exist no prerequisites for omitting scaffolding.

In constructional terms, bridge MB-B is threatened by a disaster. The application of protection measures is highly recommended.
Both functioning bridges and the remains of the other two bridges (MBR-1 and MBR-2) constitute the historical heritage of mankind. Despite this fact, none of them has been appropriately described or exhibited.

\section{References}

[1] Mao Yisheng, History of ancient bridge technology, Beijing Press, 1986, p.4.

[2] ChinaDaily, Ruins of ancient bridges discovered in Xi'an, http://www.kaogu.cn/en/News/Academic_activities/2015/0120/48 996.html [24.10. 2017].

[3] Jansen A., Bronze Age Highways at Mycenae, Echos du Monde Classique. Classical Views. Classical Association of Canada, University of Calgary Press, 41, 16, 1997; 1-16.

[4] Simpson H.R., Hagel D.K., Mycenaean Fortifications, Highways, Dams and Canals. ISBN 10: 9170812128 / ISBN 13: 9789170812125. Published by Paul Aströms Förlag, 2006, p. 254.

[5] Bougia P., Ancient Bridges in Greece and Coastal Asia Minor, Dissertation, University of Pennsylvania. 1996

[6] Briegleb J., Die vorrömischen Steinbrücken des Altertums, Technikgeschichte, 1971, 38 (3): 255-260 (258)

[7] Nakassis A., The Bridges of Ancient Eleutherna, The Annual of the British School at Athens, 2000, 95: 353-365.

[8] Karas S., Kowal M., The Mycenaean bridges - technical evaluation trial. Roads and Bridges 14, 4, 2015, 285-302.

[9] Howard Carter's notes made in preparation of the complete publication of Tutankhamun's tomb. Ed. by Sue Hutchison, Hana Navrátilová and Jaromir Malek. Sourced from http://www.griffith.ox.ac.uk/gri/4tutchar.html. [12.09.2017].

[10] Karas S., History of Sustainable Bridge Solutions, 1. Chapter in Structural Bridge Engineering, 2016, InTech.

[11] Shank G., Cunningham D.J., Modeling the six modes of Peircean abduction for educational purposes. https://www.cs.indiana.edu/event/maics96/Proceedings/shank.htm 1 [19.10.2017].

[12] Reilly F.E., Charles Peirce's theory of scientific method. ISBN 08232-0880-X. Fordham University Press, 1970, p. 33.

[13] Cohen M.R., Nagel E., An introduction to logic and scientific method. Routledge \& Kegan Paul Ltd, 1934, p. 202. 